\author{
Andrzej Lewiński \\ Prof. dr hab. inż. \\ Uniwersytet Technologiczno - Humanistyczny im K. \\ Pułaskiego w Radomiu \\ a.lewinski@uthrad.pl

\section{Tomasz Perzyński} \\ Dr hab. inż. \\ Uniwersytet Technologiczno - Humanistyczny im K. \\ Pułaskiego w Radomiu \\ t.perzynski@uthrad.p
}

DOI: 10.35117/A_ENG_19_09_01

\title{
Telematics as a future method for improving the safety of rail transport
}

\begin{abstract}
The paper shows how the development of telematics systems affects the field of railway traffic management and control. It presents current and future solutions that can significantly improve safety. A mathematical apparatus in the form of Markov processes was proposed for analysis.
\end{abstract}

Keywords: Rail systems; Safety; Models of the systems

\section{Introduction}

The purpose of introducing new systems, including ERTMS/ETCS, is to increase the functionality of rail transport, [7]. Despite the application of new solutions, the level of security, concerning onboard devices or systems in the control center, cannot be reduced to the requirements of RAMS (Reliability, Availability, Maintainability, and Safety) contained in the PN-EN 50126 standard, [3], [6]. Railway traffic management and control systems must be constructed under the requirements and applicable standards that define such requirements as the Tolerable Hazard Rate or the method of coding transmitted information. The paper shows that system readiness can be defined as the probability of a non-occurrence of a critical event. The presented method of estimating readiness was based on the Markov chain. The presented models correspond to the systems already in use and reference was made to the proposals for the implementation of systems using open transmission standards.

\section{Fundamentals of safety analysis of rail traffic management and control systems}

In the newly designed rail traffic management and control systems, one of the basic indicators characterizing safety is the so-called tolerable risk level - THR. The estimated value of this indicator must fall within the range assumed for a given group of devices. This indicator is referred to as, [11]:

$$
T H R=\prod_{i=1}^{n} \frac{\lambda_{i}}{t_{d_{i}}{ }^{-1}} \cdot \sum_{i=1}^{n}{t_{d_{i}}}^{-1}
$$

where:

$\lambda_{i}$ - intensity of damage for the channel $i$,

$t_{d_{i}}{ }^{-1}$ - system response time to error since it was created for the channel $i$. 
Secure computer systems usually working in a redundant structure $(2 z 2,2 z 3)$ with the independence of data processing channels guarantee a low probability of a critical failure. It should be added that safety also depends on the time of detection of single and multiple defects. With one processing channel, the formula (1) analysis boils down to determining the damage intensity factor.

For a two-channel system, formula (1) takes the form $2 \lambda \mathrm{t}_{\mathrm{d}} / \mathrm{t}_{\mathrm{FT}}$. In this case, the critical damage intensity has been reduced to a degree $2 t_{d} / t_{T F}\left(t_{d}\right.$ - response time to damage, $t_{T F}$ average time to failure in the channel). For rail traffic management and control systems included in the highest fourth SIL (Safety Integrity Level), THR values should be in the range $10^{-9} \leq T H R<10^{-8}$.

In addition to the THR indicator mentioned above, rail traffic management and control systems (hardware, software) can be analyzed using FMEA, FTA or Markov chain, [8], [9], [14]. The latter uses continuous-time processes that correlate with the Poisson process. If the transition from one condition to another caused by a certain stream of events is a Poisson stream, then the random process in the system is a Markov chain of a step and continuoustime. System transition from condition $S_{i}$ to condition $S_{j}$ is designated by a function $\lambda_{i j}(t)$, where $\lambda$ is the intensity of the damage or the intensity of the transitions. The matrix describing the chain corresponds to a graph that can be written as a system of differential equations. The differential equation for the $i^{\text {th }}$ condition is shown in the following equation:

$$
\frac{d P_{i}(t)}{d t}=-P_{i}(t) \sum_{i=1}^{n} \lambda_{i j}(t)+P_{j}(t) \sum_{j=1}^{n} P_{i}(t) \lambda_{j i}(t)
$$

where $i=1,2,3, \ldots ., n, P_{i}(t)$ - are the probability distributions of individual conditions.

In order to resolve such a system, initial conditions must be assumed:

$$
P_{i}(0)=P_{i}
$$

where $i=1,2,3, \ldots ., n$

This method in stationary conditions allows obtaining a system of linear algebraic equations. This is possible by using Laplace transform:

$$
\tilde{f}(s)=L[f(t)]=\int_{0}^{\infty} e^{-s t} f(t) d t
$$

Using the properties of the transform:

$$
L\left[f^{\prime}(t)\right]=s \tilde{f}(s)-f(0)
$$

the system of differential equations can be transformed into an algebraic equation, thanks to which Laplace transforms of appropriate probabilities $P_{i}$ can be determined:

$$
s \tilde{P}(s)-P_{i}(0)=-\tilde{P}_{i}(s) \sum_{j=1}^{n} \lambda_{i j}+\sum_{i=1}^{n} \lambda_{i j} \tilde{P}_{j}(s)
$$

The system of equations presented in the operator form is solved as a classic system of linear equations. When calculating probability limits, a limit thorem is used:

$$
\lim _{t \rightarrow \infty} s P(s)=\lim _{t \rightarrow \infty} P(t)
$$


Due to the way of working and reacting to the damage, according to the theory of reliability, some rail traffic control systems can be characterized as systems with repair (in the modeling of railway traffic control systems, a system without repair is also used). The system model with repair assumes cyclical recovery from disability (Fig. 1).

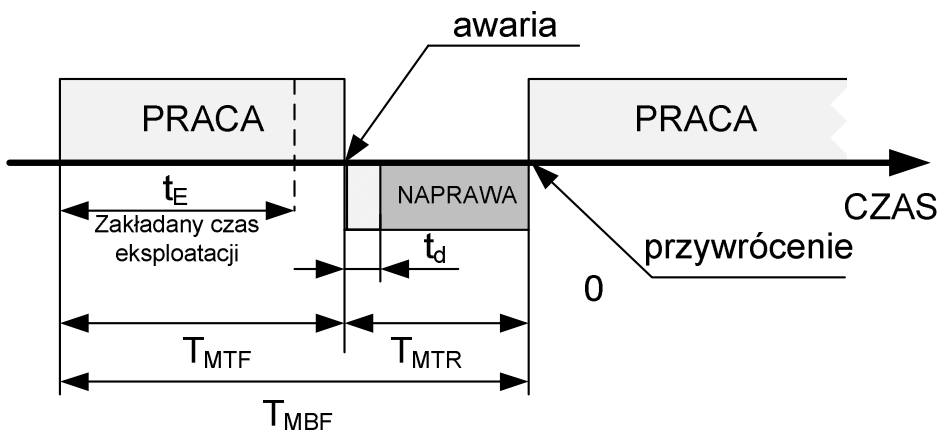

1. Characteristics of the system with repair

For the system with repair, the concept of system readiness has been introduced - the probability that the object is operational at the moment $t$ from the start of the operation. It is the sum of the probabilities of the object being in the conditions of efficiency:

$$
A(t)=\sum_{i=0}^{n} P_{i}(t)
$$

where $n$ is the last condition of efficiency.

The readiness factor of the repairable facility $\mathrm{A}$ is expressed as a limit value, which means that the facility will be operational after a sufficiently long period of operation:

$$
A=\lim _{t \rightarrow \infty} A(t)
$$

The readiness factor of the repairable object can be calculated based on the Laplace transform boundary property at $s \rightarrow 0$.

In srk systems, safety is intuitively associated with not being in the condition of multiple damages. That is why the concept of so-called controlled damage. All single damages should be controlled (detected in a relatively short time), while multiple damages, related to the simultaneous occurrence of a fault in $\mathrm{n}$ processing channels, decide on the occurrence of a dangerous situation (assuming a sufficiently short response time of multiple fault detection). Redundant systems do not have to be safe, only their reliability ratios increase significantly, especially the time to critical damage (safety failure). As a rule, these are systems that tolerate damage to individual elements, working to damage the last element (fault-tolerant).

In safe systems (the general model is shown in Fig. 2), two groups of end conditions are introduced:

- condition of dangerous damages,

- condition of controlled damages.

A fail-safe system is a system in which being in a controlled failure condition leads to a safety response - emergency control. In Fig. 2, condition 1 is a condition of controlled damage, the transition to this condition is ensured by, among others telematics solutions. 


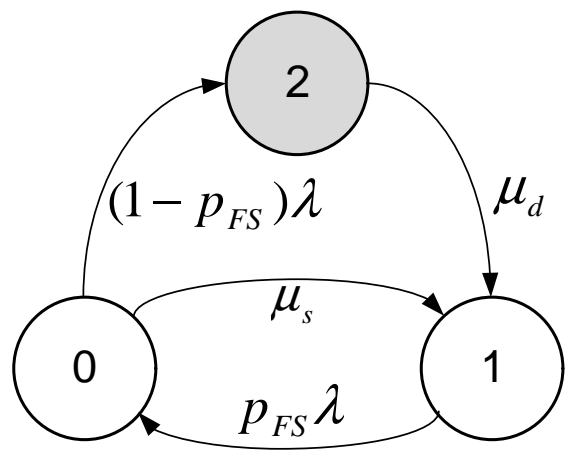

2. General model of a fail-safe system

The model presented in Figure $\mathbf{2}$ is a stationary and homogeneous Markov chain. The following conditions are distinguished in this model:

- 0 - condition of correct operation,

- 1 - condition of controlled damages,

- 2 - condition of dangerous damages (catastrophic).

with markings:

- $\mu_{s}, \mu_{d}$-the intensity of repairs in the condition of controlled damages and a condition of dangerous damages,

- $\lambda$ - the intensity of damage,

- $p_{F S}-$ the probability of controlled damage (e.g., probability of switching at the time of damage).

By solving the system of state equations, one can calculate the limit value of probability P2, i.e. the probability of being in a state of critical damage:

$$
P 2=\frac{\lambda \mu_{S}\left(1-p_{F S}\right)}{\mu_{S} \mu_{d}+\lambda\left(\mu_{S}-p_{F S} \mu_{S}+\mu_{d}\right)}=\frac{\lambda}{\mu_{s}}\left(1-p_{F S}\right)
$$

The readiness factor for the model in Fig. 2 is then equal A $=1$ - P2.

\section{Dispatcher system security}

The modern dispatching system is an example of a multi-computer system, in which the failure of one of the computers causes switching to the work of another of the computers, the backup, but working in the hot standby mode. An example of such a system may be the ILTOR-2 system known in Poland, shown in Fig. 3, whose model as a system with repair, is shown in Fig. 4.

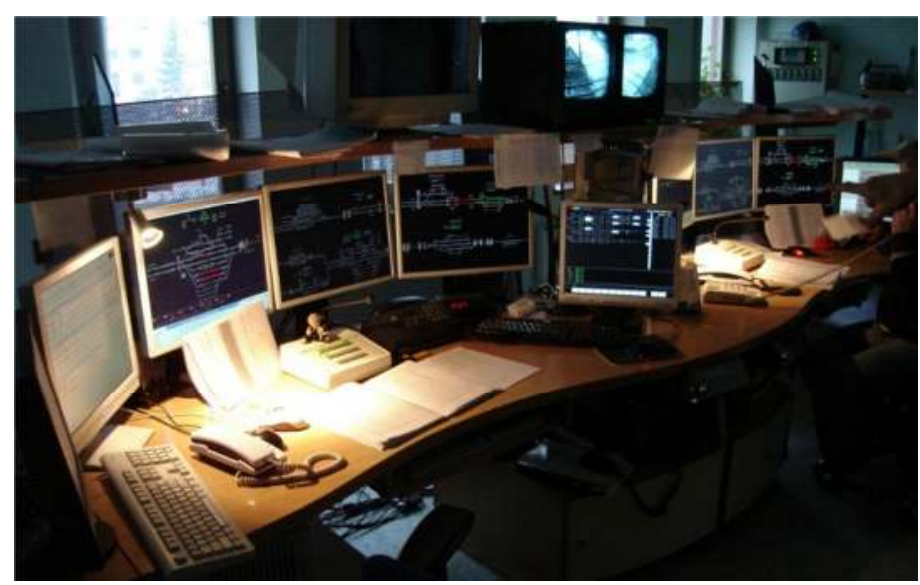

3. Contemporary rail traffic control center - ILTOR-2 


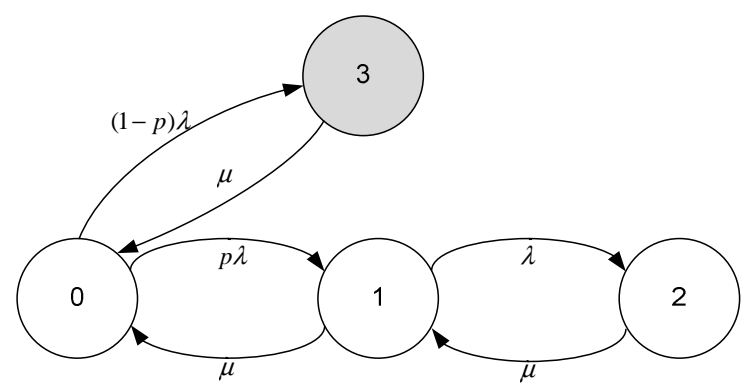

4. Model of the system with repair - the control center

The switch with the probability of correct switching $p$ is responsible for switching to the standby computer. In this model we distinguish the following conditions:

- 0 - main and backup functional computer,

- 1 - reserve work status,

- 2 - state of controlled damages (turning off the standby computer working as the main one),

- 3 - the state of dangerous damage, in which the main computer was damaged, and the standby computer as a result of incorrect switching did not take over the control function.

By solving the system of state equations, the probability P3 was calculated:

$$
P 3=\frac{(\lambda-p \cdot \lambda) \cdot \mu^{2}}{\mu \cdot\left(p \cdot \lambda^{2}+\mu \cdot(\lambda+\mu)\right)} \approx \frac{\lambda}{(1-p) \mu}
$$

Assuming $\lambda=10^{-5} h^{-1}, \mu=1 h^{-1}$ and $p=1-10^{-6}$ the limit value of the readiness factor for $t \rightarrow \infty$ equals: $A=1-P 3=0,99999999$.

\section{ERTMS/ETCS system security}

The ETCS system (European Train Control System) is one of the components of the ERTMS system (European Rail Traffic Management System), [10]. The goal of the ERTMS system is to ensure the interoperability of rail transport in EU member states. This is because the railway managers of the member countries have developed their solutions regarding the technical specifications for rail traffic control and management systems. Unification of various control systems will allow "railway without borders". With regard to safety, the ERTMS system can contribute to the elimination of events that may cause a threat to railway traffic, such as ignoring the "stop" signal and exceeding the speed limit on a given section. The solutions used in ERTMS allow for higher speeds of rolling stock and higher capacity while maintaining a high level of security, [4], [5], [13]. The ERTMS/ETCS system can be configured to work in one of the levels [1]:

- level 1 - a solution based on the transmission of driving licenses by means of balise,

- level 2 - GSM-R is used to transmit driving permits, besides, the track is equipped with radio block centers),

- level 3 - is a development of level two and enables driving following the movable block gap. At this level, axle counters and track circuits are omitted.

Elements of the ETCS system are shown in Fig. 5 [2]. 

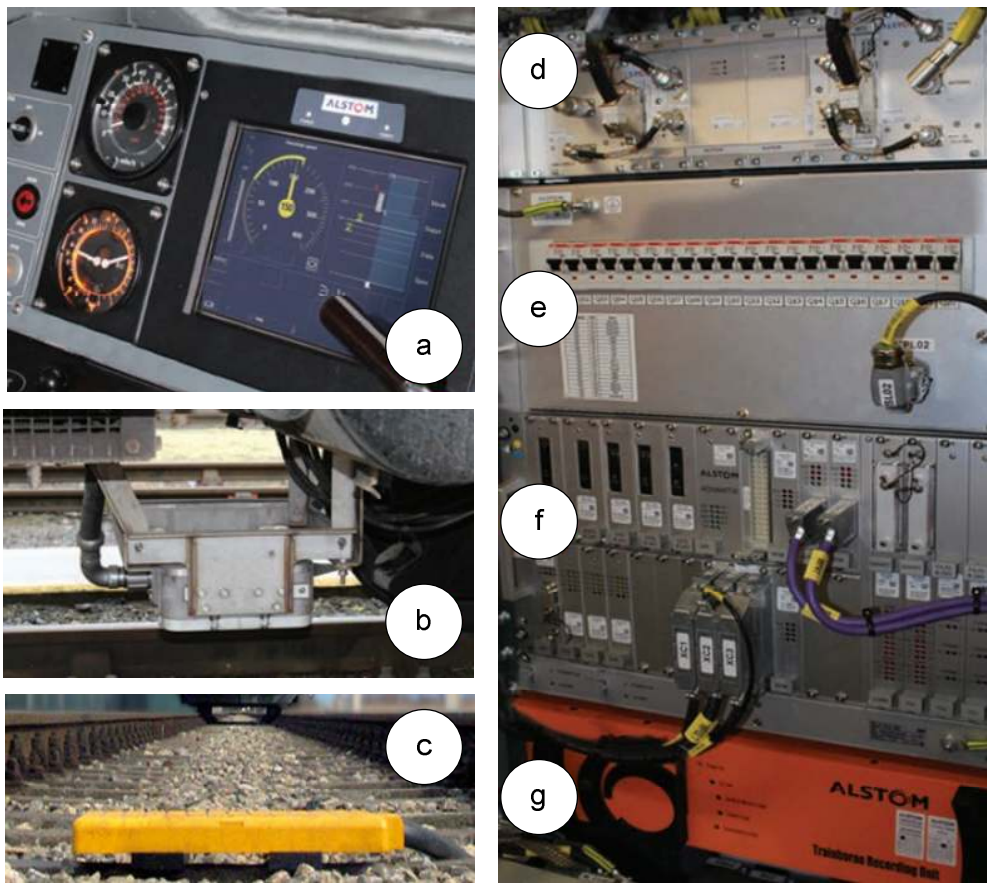

5. ETCS system a) driver interface, b) antenna for track-vehicle communication c) eurobalise d) GSM subsystem e) interface unit f) on-board computer g) data recording module, [based on 2]

Fig. 6 shows the model for the ERTMS / ETCS system.

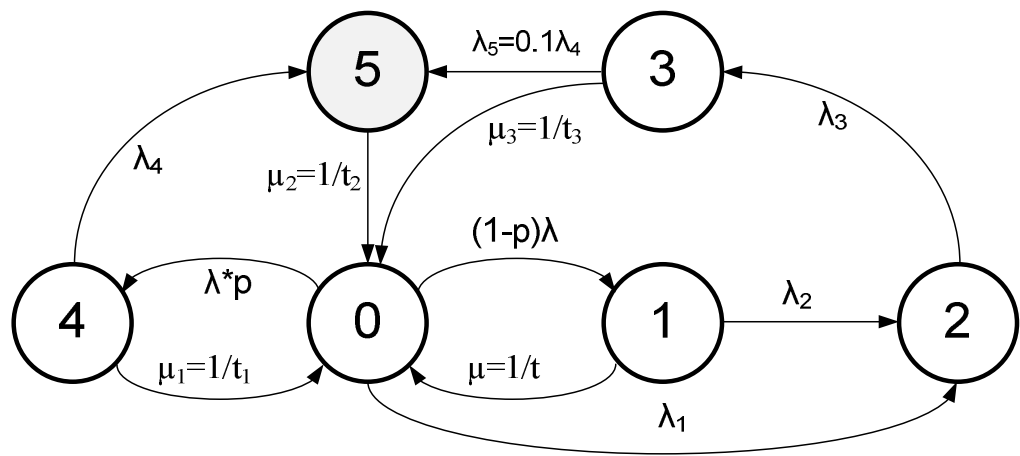

6. Model for the ERTMS/ETCS system

In the model, there are:

- Condition 0 - state of normal operation.

- Condition 1 - data reception status. Implementation of commands by the system.

- Condition 2 - controlled damage (e.g. no GSM-R transmission). Automatic train stop.

- Condition 3 - emergency vehicle displacement.

- Condition 4 - train running as indicated by trackside signals.

- Condition 5 - critical condition, uncontrolled.

We can write state equations for the model in Fig. 5: 


$$
\left\{\begin{array}{l}
\frac{d P_{0}(t)}{d t}=-\left[(1-p) \lambda+\lambda_{1}+\lambda p\right] P_{0}(t)+\mu P_{1}(t)+\mu_{1} P_{4}(t)+\mu_{3} P_{3}(t)+\mu_{2} P_{5}(t) \\
\frac{d P_{1}(t)}{d t}=(1-p) \lambda P_{0}(t)-\mu P_{1}(t)-\lambda_{2} P_{1}(t) \\
\frac{d P_{2}(t)}{d t}=\lambda_{2} P_{1}(t)+\lambda_{1} P_{0}(t)-\lambda_{3} P_{2}(t) \\
\frac{d P_{3}(t)}{d t}=\lambda_{3} P_{2}(t)-\mu_{3} P_{3}(t)-\lambda_{5} P_{3}(t) \\
\frac{d P_{4}(t)}{d t}=\lambda P_{0}(t)-\mu_{1} P_{4}(t)-\lambda_{4} P_{4}(t) \\
\frac{d P_{5}(t)}{d t}=\lambda_{4} P_{4}(t)+\lambda_{5} P_{3}(t)-\mu_{2} P_{5}(t)
\end{array}\right.
$$

In the model from Fig. 6, it was assumed that the most undesirable state is state 5 . The limit probability of being in state $\mathrm{P}_{5}$ is:

$\mathrm{P}_{5}(\mathrm{t})_{\mathrm{t} \rightarrow \infty}=\left[\left(\mu \lambda_{1}+\left(\lambda+\lambda_{1}\right) \lambda_{2}\right) \lambda_{3}\left(\mu_{1}+\lambda_{4}\right) \lambda_{5}+\mathrm{p} \lambda \lambda_{3}\left(\mu \lambda_{4}\left(\mu_{3}+\lambda_{5}\right)+\left(\mu_{3} \lambda_{4} \mu_{1} \lambda_{5}\right)\right)\right] /\left[\mathrm{p} \mu_{2} \mu_{3} \lambda \lambda_{2} \lambda_{3}+\right.$ $\mu_{2} \mu_{3} \lambda \lambda_{2} \lambda_{4}-\mathrm{p} \mu_{2} \mu_{3} \lambda \lambda_{2} \mu_{2} \mu_{3} \lambda_{1} \lambda_{2} \lambda_{4}+\mu_{2} \mu_{3} \lambda_{3} \lambda_{4} \mathrm{p} \mu_{2} \mu_{3} \lambda \lambda_{3} \lambda_{4}+\mu_{2} \mu_{3} \lambda_{2} \lambda_{3} \lambda_{4} \lambda \lambda_{2} \lambda_{3} \lambda_{4}-\mathrm{p} \mu_{2} \lambda \lambda_{2} \lambda_{3} \lambda_{4}+$ $\mathrm{p \mu}_{3} \lambda \lambda_{2} \lambda_{3} \lambda_{4}+\mu_{2} \lambda_{1} \lambda_{2} \lambda_{3} \lambda_{4}+\left(\left(\mu_{2}\left(\lambda+\lambda_{1}\right) \lambda_{2}+\left(\lambda+\lambda_{1}\right) \lambda_{3}+\mu_{2}\left(\lambda+\lambda_{2}\right) \lambda_{3}\right) \lambda_{4}+\mathrm{p} \mu_{2} \lambda\left(\lambda_{2} \lambda_{3}-\left(\lambda_{2}+\right.\right.\right.$ $\left.\left.\left.\lambda_{3}\right) \lambda_{4}\right)\right) \lambda_{5}+\mu\left(\mathrm{p} \lambda \lambda_{3}\left(\mu_{2}+\lambda_{4}\right)\left(\mu_{3}+\lambda_{5}\right)+\mu_{1}\left(\lambda_{1} \lambda_{3} \lambda_{5}+\mu_{2}\left(\lambda_{1} \lambda_{3}+\mu_{3}\left(\lambda_{1}+\lambda_{3}\right)+\left(\lambda_{1}+\lambda_{3}\right) \lambda_{5}\right)\right)+\lambda_{4}\right.$ $\left.\left(\lambda_{1} \lambda_{3} \lambda_{5}+\mu_{2}\left(\lambda_{1} \lambda_{3}+\mu_{3}\left(\lambda_{1}+\lambda_{3}\right)+\left(\lambda_{1}+\lambda_{3}\right) \lambda_{5}\right)\right)\right)+\mu_{1}\left(\left(\lambda-p \lambda+\lambda_{1}\right) \lambda_{2} \lambda_{3} \lambda_{5}+\mu_{2}\left(\lambda_{1} \lambda_{2} \lambda_{3}+\mu_{3}\left(\lambda_{2}\left(\lambda_{1}+\right.\right.\right.\right.$ $\left.\left.\left.\left.\left.\lambda_{3}\right)-(-1+\mathrm{p}) \lambda\left(\lambda_{2}+\lambda_{3}\right)\right)+\lambda_{2}\left(\lambda_{1}+\lambda_{3}\right) \lambda_{5}-(-1+\mathrm{p}) \lambda\left(\lambda_{2} \lambda_{3}+\left(\lambda_{2}+\lambda_{3}\right) \lambda_{5}\right)\right)\right)\right]$

Assuming parameters (table 1): the threshold value of the readiness factor was calculated depending on the probability p of the vehicle not using the ERTMS/ETCS system, as shown in Table 2.

Tab. 1. Assumptions for the model from Fig. 6

\begin{tabular}{|c|c|c|c|c|c|c|c|c|c|}
\hline Parameter & $\lambda$ & $\lambda_{1}, \lambda_{2}$ & $\lambda_{3}$ & $\lambda_{4}$ & $\lambda_{5}$ & $\mu$ & $\mu_{1}$ & $\mu_{2}$ & $\mu_{3}$ \\
\hline Value $\left[\mathrm{h}^{-1}\right]$ & 6 & 0.00001 & 1 & 0.001 & $10 \% \lambda_{4}$ & 30 & $2 \mu$ & 0.083 & 1 \\
\hline
\end{tabular}

Tab. 2. Calculations for the model in Fig. 6

\begin{tabular}{|c|c|c|c|c|c|}
\hline Probability $p$ & 0.1 & 0.3 & 0.5 & 0.7 & 0.9 \\
\hline Value $A_{t \rightarrow \infty}$ & 0.99989 & 0.99969 & 0.99947 & 0.99925 & 0.99902 \\
& 8 & 1 & 6 & 4 & 4 \\
\hline
\end{tabular}

\section{Train collision exclusion system - new solutions}

The proposed concept of an additional system informing the driver about another train on the route assumes: data transmission over a distance of $10 \mathrm{~km}$, the possibility of using the open data transmission standard, installation on a single-track line, [12]. The solution may function as an additional panel installed in the driver's cab. If another train within the range of the transmission module is detected, the system begins to inform about the distance from it. The system can be particularly important in the event of collision traffic on one track. It is enough to mention two tragedies in which a total of 35 people were killed - a collision in Bari-Barletta (Italy, 2016) and Bad Aibling (Germany, 2016). Figure 7 proposes a model that includes an additional system to inform the driver about another train on the route. 


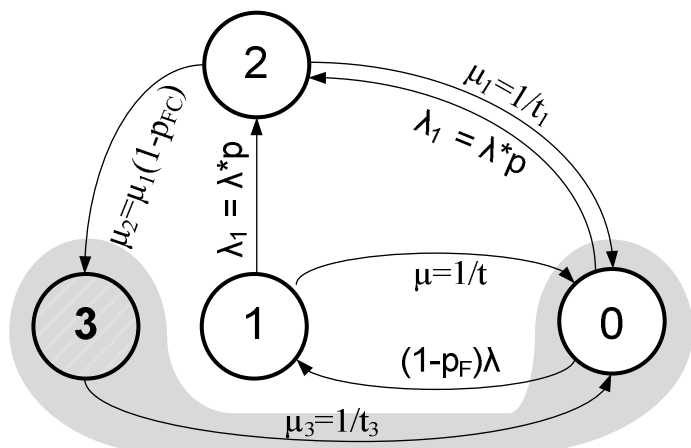

7. Model of warning system about the possibility of a collision on the route

In the model, there can be distinguished:

- condition 0 - the condition of correct operation,

- condition 1 - waiting for information about the train within range of the radio module,

- condition - reception of critical data,

- condition - the condition of critical situation.

where:

- $\lambda$ - the intensity of messages sent along the trail,

- $\lambda 1$ - the intensity of sent critical messages,

- $\mathrm{p}$ - the probability of a critical situation,

- $\mathrm{pFC}$ - the probability of correct response,

- $\mu$ - service time,

- $\mu 1$ - time of handling critical situation,

- $\mu 2$ - the intensity of transition to a dangerous state,

- $\mu 3$ - recovery time.

Assuming parameters: $\lambda=12 / \mathrm{h}, \lambda_{1}=\lambda \cdot \mathrm{p}, \mathrm{p}=0.1 \%, \mu_{1}=30 / \mathrm{h}, \mu_{2}=\mu_{1}\left(1-\mathrm{p}_{\mathrm{FC}}\right), \mathrm{p}_{\mathrm{FC}}=0.999, \mu_{1}=4 \mathrm{~h}$ and by solving the system of state equations for the model from Fig. 7, the limit value of the readiness factor is:

$$
A(t) \lim _{t \rightarrow \infty}=\frac{\lambda_{1} \mu_{2}}{\left(\mu_{1}+\mu_{2}\right) \cdot \mu_{3}+\lambda_{1} \cdot\left(\mu_{2}+\mu_{3}\right)}=0,999952
$$

In the absence of an additional system, the model in Fig. 7 is limited to conditions 1 and 3 with the intensity of transition $\lambda_{1}$ to state 3 . In this case, the limit value of the readiness factor under the same assumptions $\lambda_{1}$ and $\mu_{3}$ is 0.954198 .

\section{Conclusions}

Mathematical analysis carried out in the paper showed how new technologies originating in the field of telematics increase the level of security. Presented and modeled ERTMS/ETCS system is currently the only solution constituting an interface between various rail traffic management and control systems. As pointed out by the European Court of Auditors, the cost of equipping the European rail network (TEN-T) with ERTMS may amount to EUR 188 billion [15]. There is no doubt, however, that the system is necessary to ensure interoperability. The authors also presented the concept of a system that by using the public wireless transmission standard can contribute to the improvement of railway traffic safety. The presented concept is an extension of solutions used in other modes of transport. 


\section{Source materials}

[1] Białoń A., Gradowski P., Toruń A.: „Nowoczesne systemy zarządzania ruchem kolejowym (ERTMS)". Problemy Kolejnictwa - Zeszyt 148, 2009

[2] UNIFE - The European Rail Industry „International freight corridors equipped with ERTMS". ERTMS Factscheet, no. 15, 2014

[3] Norma PN-EN 50126:2002 (U) Zastosowania kolejowe. Specyfikowanie i wykazywanie Nieuszkadzalności, Gotowości, Obsługiwalności i Bezpieczeństwa (RAMS). Część 1: Wymagania podstawowe i procesy ogólnego przeznaczenia

[4] Lewiński A., Torun A., Gradowski P: "Modeling of ETCS with respect to functionality and safety including Polish Railways conditions", Communications In Computer And Information Science, Telematics - Support Of Transport (471), Springer-Verlag Berlin Heidelberg 2014

[5] Lewiński A., Toruń A.: „The efficiency analysis of train monitoring system applying the Changeable Block Distance method", Communications in Computer and Information Science (395), Springer-Verlag Berlin Heidelberg 2013

[6] Lewiński A.: „Nowoczesne systemy telematyki kolejowej”, Wydawnictwo Politechniki Radomskiej, Radom, 2012, ISBN 978- 83- 7351-506-2

[7] Winter P. and other: Compendium on ERTMS. ISBN 978-3-7771-0396-9, UIC, (1st edition), 2009

[8] Qiu, S., Sallak, M., Schön, W., Cherfi, Z.,"Modeling of ERTMS Level 2 as an SoS and Evaluation of its Dependability Parameters Using Statecharts". IEEE Systems Journal. 8. 10.1109/JSYST.2013.2297751, 2014

[9] Carnevali L., Flammini F., Paolieri M., Vicario E. (2015) Non-Markovian Performability Evaluation of ERTMS/ETCS Level 3. In: Beltrán M., Knottenbelt W., Bradley J. (eds) Computer Performance Engineering. EPEW 2015. Lecture Notes in Computer Science, vol 9272. Springer

[10] Młyńczak J., Toruń A., Bester L., "European Rail Traffic Management System (ERTMS)". In: Sładkowski A., Pamuła W. (eds) Intelligent Transportation Systems Problems and Perspectives. Studies in Systems, Decision and Control, vol 32. SpringerVerlag Berlin Heidelberg 2016

[11] Lewiński A., Perzyński T.: "The reliability and safety of railway control systems based on new information technologies". Communications In Computer and Information Science. Transport Systems Telematics (104), Springer 2010

[12] Perzyński T. "Wybrane systemy telematyki w bezpieczeństwie i zarządzaniu transportem lądowym I śródlądowym," Seria Monografie (201), Wydawnictwo Politechniki Radomskiej, Radom, Radom 2016

[13] Lewiński A., Toruń A.: " The Changeable Block Distance System Analysis", Communications in Computer and Information Science (104), Springer-Verlag Berlin Heidelberg 2010

[14] Leitner, Bohuš. (2017). A General Model for Railway Systems Risk Assessment with the Use of Railway Accident Scenarios Analysis. Procedia Engineering. 187. 150-159. 10.1016/j.proeng.2017.04.361

[15] European Court of Auditors. Special report no 13/2017: A single European rail traffic management system: will the political choice ever become reality?. Luxembourg 2017 